\title{
THE NEURAL ARCHITECTURE OF BINOCULAR VISION
}

\author{
V. A. CASAGRANDE and J. D. BOYD \\ Nashville, Tennessee
}

The brain is remarkable in its ability to match images from the left and right eyes to produce a seamless single image of the world. Not only are the slightly different monocular views of the world fused to produce a single image, but also, in many frontaleyed mammalian species, this single image provides additional information about stereoscopic depth. What components of neural architecture are responsible for these precepts? In this review we briefly outline current views of the neural hardware that have been proposed to be responsible for binocular single vision. We will focus primarily on the visual system of primates but mention other mammalian species where relevant. Within this framework we consider three issues which remain controversial. First, do all classes of retinal ganglion cells contribute signals that are important to stereoscopic depth perception or only one class? Second, does the dorsal lateral geniculate nucleus (LGN) play a special role in binocular vision? Finally, are ocular dominance columns of primary visual cortex important to binocularity?

\section{OVERVIEW OF BINOCULAR CONNECTIONS}

The visual pathways from the retina to the primary visual cortex (also called V1 or striate cortex) have been well studied in a variety of mammals. ${ }^{1}$ As shown in Fig. 1, for a generic primate, the lateral geniculate nucleus (LGN) receives axons from ganglion cells in the nasal half of the contralateral retina and from the temporal half of the ipsilateral retina. All placental mammals segregate ocular input within the LGN although the number of layers varies from two in rodents to as many as eight in some humans. That there are more than two layers in the LGN in most species reflects the segregation within this structure not only of inputs from the left and

Correspondence to: V. A. Casagrande, Department of Cell Biology, Vanderbilt Medical School, Medical Center North RM C2310, Nashville, TN 37232-2175, USA. Fax: +1 (615) 343-4539. e-mail: vivien.casagrande@mcmail.vanderbilt.edu. right eyes, but also of inputs from functionally distinct classes of retinal ganglion cells that exist in each retina. Thus, in primates there are two magnocellular (M) layers, one for each eye; two or more pairs of parvocellular $(\mathrm{P})$ layers; and variably located sets of very small cells, which we will refer to here as the koniocellular (K) layers. ${ }^{2}$

The LGN also receives visual input from a variety of other sources including areas of the cortex, midbrain and brainstem. ${ }^{2}$ Of these sources four provide retinotopically organised binocular input. The richest source of this input comes from V1. The binocular cells in layer VI of V1 send a heavy excitatory (aspartate) projection back to all layers of the LGN (see Fig. 1). In the cat LGN, synapses from this pathway, which ends on both excitatory relay cells and inhibitory (GABAergic) interneurons, ${ }^{3}$ outnumber those from the retina 10 to $1 ;{ }^{4}$ this ratio has not been examined in primates. Other visually driven sources of excitatory axons to the primate LGN come from the superior colliculus and parabigeminal nucleus which terminate almost exclusively on $\mathrm{K}$ cells, ${ }^{5,6}$ and the pretectum, which targets all geniculate layers, ${ }^{7}$ all of the latter structures contain binocular cells.

The LGN projects ipsilaterally to the primary visual cortex (V1). Like the LGN, V1 in each hemisphere receives information about the contralateral visual field through both eyes and from three distinct classes of cells. For many primate species (but not all; see below), the same double segregation of eye and functional type that occurs in the LGN also occurs in V1, but whereas the LGN achieves both types of segregation by creating additional laminae, V1 utilises laminar segregation for functional class, and a tangential segregation for eye specificity. ${ }^{2}$ (An interesting exception is the tree shrew visual cortex, which has a laminar segregation of both functional class and eye specificity. ${ }^{8-11}$ ) Thus, in species that segregate ocular inputs, the primary input layer, layer 4 , is not only split into $\mathrm{M}$ and $\mathrm{P}$ 


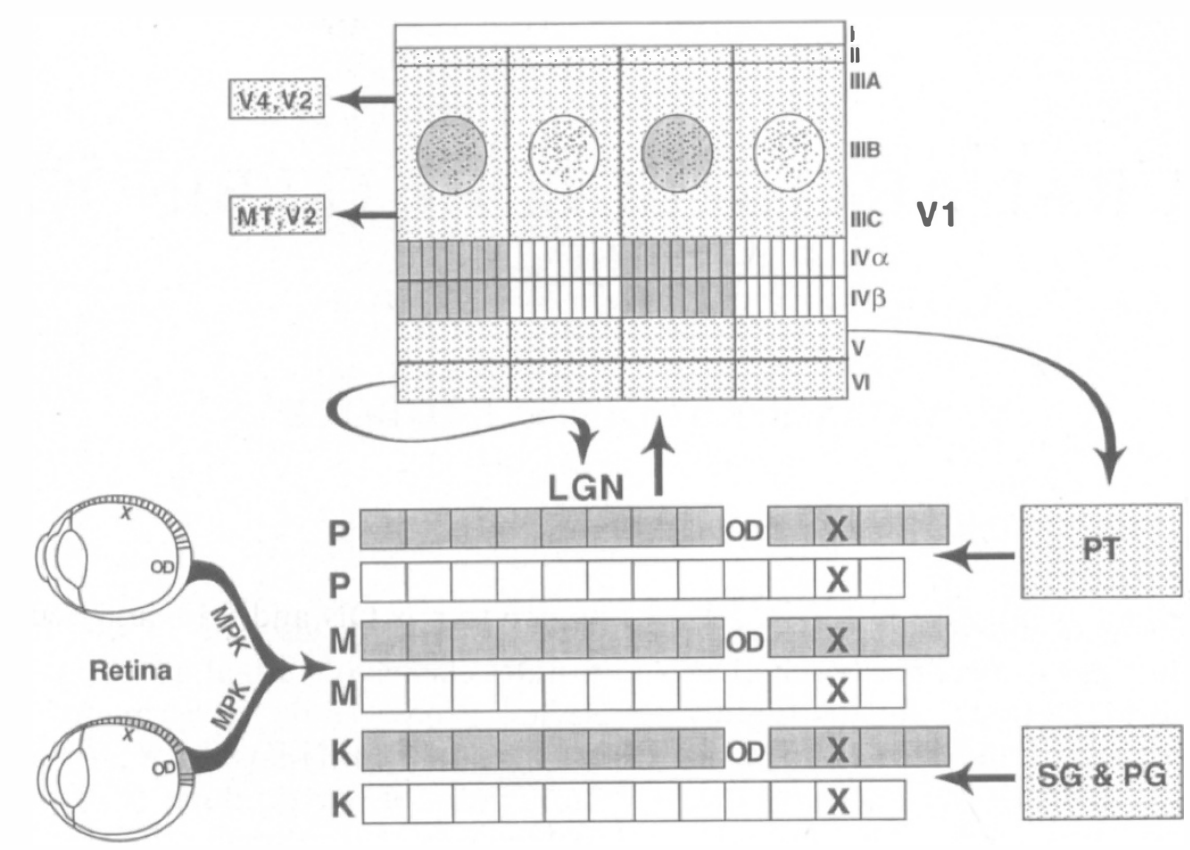

Fig. 1. A schematic diagram of the connections of the left and right eye with the right hemisphere in a primate. ON and $O F F$ centre magnocellular $(M)$, parvocellular $(P)$ and koniocellular $(K)$ retinal ganglion cells from the left nasal retina and right temporal retina send axons to different layers of the right lateral geniculate nucleus $(L G N)$. The axons from each eye terminate retinotopically such that points on the retina $(X)$ that represent the same point in visual space are in register in each layer. $A$ gap appears in all LGN layers where the retina is blind at the optic disc (OD). The LGN also receive binocular visual input from other direct or indirect retinotopically organised sources including the pretectum (PT), the superior colliculus (SC), parabigeminal nucleus $(P G)$ and primary visual cortex (V1). Projections to V1 from the LGN $M$ and $P$ layers end in layers $I V \alpha$ and IV $\beta$, respectively, and are also segregated into ocular dominance columns in some species. In bush babies and macaque monkeys, the cytochrome oxidase (CO) rich blobs (circles in layer IIIB) contain a higher percentage of monocular cells. The remaining layers contain a high percentage of binocular cells. Cells in layer IIIA project to visual areas 2 and 4 and cells in layer IIIC project to V2 and the middle temporal visual area (MT). Cells in layer VI project to the LGN and cells in layer $V$ project to the SC and PT. Areas driven monocularly by the right eye are shown in white; areas driven monocularly by the left eye are shown in grey; areas driven binocularly are stippled. Roman numerals refer to cortical layers. See text and also Casagrande and Kaas ${ }^{l}$ for further discussion.

sublayers but further divided into alternating columns that receive input from each eye, the ocular dominance (OD) columns (see also Fig. 1). Input from the $\mathrm{K}$ layers terminates within cortical layer III where it ends within zones which stain darkly for cytochrome oxidase (CO blobs), and within layer I. At present, it is unclear whether the $\mathrm{K}$ pathway also maintains ocular segregation in cortex, although this is likely since $\mathrm{CO}$ blobs are found in the centres of the OD columns and individual $\mathrm{K}$ LGN axons terminate only within a single $\mathrm{CO}$ blob $^{12.13}$ (The higher percentage of monocular cells recorded within the centres of macaque and bush baby CO blobs ${ }^{14,15}$ may, in part, reflect this monocular LGN input.)

Although eye-specific inputs can be segregated within layer IV, they are combined at the next stage of cortical processing, and many binocular cells are found in V1 in all layers outside of layer IV. ${ }^{16}$ That is, while neurons in LGN and layer IV of V1 generally respond only to stimulation of one eye, neurons in supra- and infra-granular layers of V1 can be driven through either eye. Some of these binocular cells are sensitive to small horizontal disparities in retinal position between the two eyes, ${ }^{17}$ such disparities occur for stimuli in front of or behind the fixation plane, making disparity-sensitive cells candidates for encoding depth information. Once ocular input is combined in V1 it remains together within all extrastriate visual areas regardless of specialisation. Thus, it seems reasonable to propose that interactions important to binocular vision and stereopsis are set up in cortical area V1.

\section{CONTRIBUTIONS OF PARALLEL PATHWAYS}

How visual cortical cells put together the signals arriving from each eye is not a trivial problem. Visual cortical cells face the problem of combining inputs not just from each eye but also from different functional classes of ganglion cells. It is well recognised that retinal ganglion cells with different physiological properties represent common points in visual space. ${ }^{18}$ Presumably such an arrangement of functional parallelism allows the visual system to process separate aspects of the visual scene more efficiently since information from a single retinal 
Binocular V1 Cells

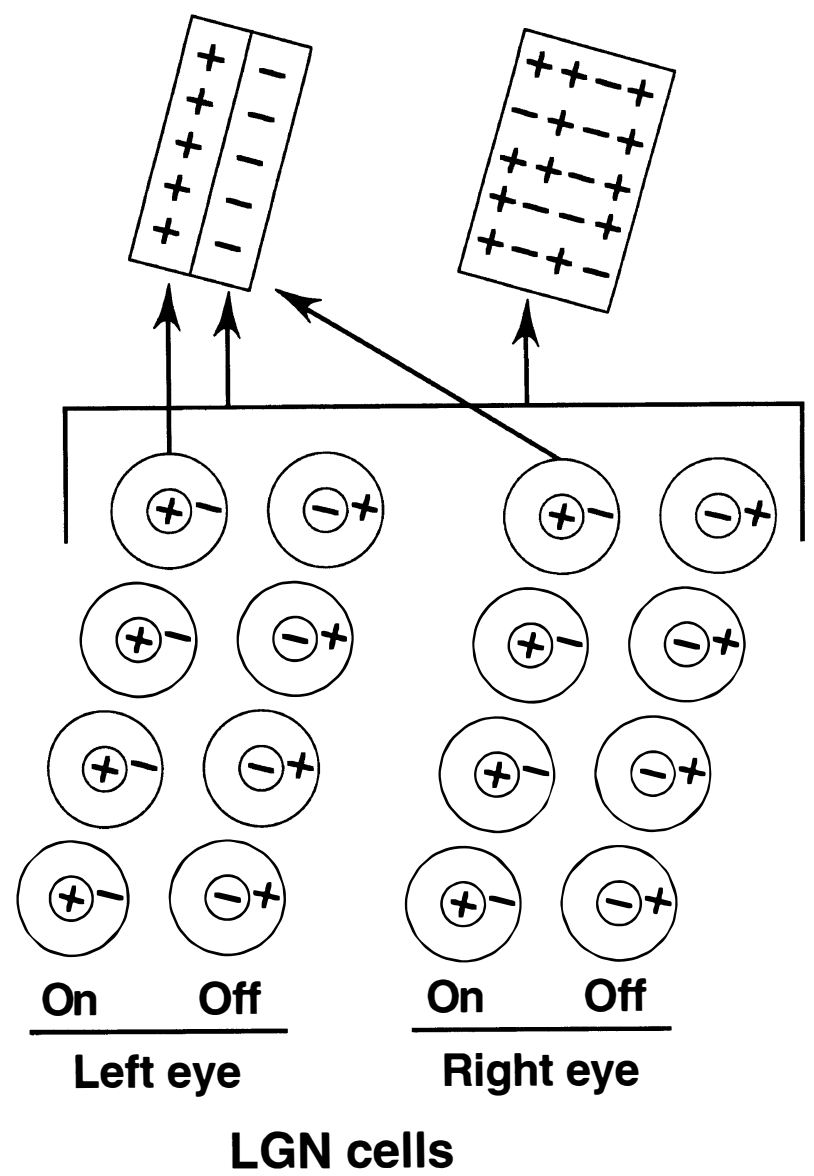

Fig. 2. Convergence of $L G N$ inputs in $V 1$ simple and complex cells. Shown are four concentric ON centre OFF surround LGN cells and four OFF centre ON surround $L G N$ cells representing each eye. Cortical binocular cells are orientation selective and exhibit the same receptive field properties (with the exception of ocular disparity) for each eye. This requires that monocular LGN cells with different centre/surround and other properties projecting to the same cell match precisely to produce the appropriate cortical receptive field structure. This figure shows two types of direct convergence from LGN cells to cortical simple and complex cells that were identified by Tanaka. ${ }^{25}$ Some simple and complex cells received projections from both $O N$ and OFF LGN cells from both eyes. Other simple cortical cells received exclusively $O N$ (as shown here) or OFF centre inputs. Convergence of the properties of primate $L G N$ inputs to V1 cells has not been studied in detail. See text for discussion.

locus travels and is processed in parallel. However, such parallelism also presents problems for binding monocular signals in cortex. For example, it is well known that, except for disparity, binocular cells in V1 exhibit the same receptive field properties for each eye. ${ }^{19}$ Yet, at the level of the LGN, separate cells signal increments and decrements in brightness $(\mathrm{ON}$ centre and OFF centre cells) and populations of cells $(\mathrm{M}, \mathrm{P}$ and $\mathrm{K})$ with distinct chromatic, spatial and temporal properties are segregated, as mentioned above, to separate LGN layers. ${ }^{2}$ Is this convergence accomplished in one step or several serial steps?

In macaque monkeys there is physiological evidence that a number of cells within the $\mathrm{M}$ target layer, IV $\alpha$, of visual cortex are monocular simple cells with ON and OFF responses ${ }^{20}$ suggesting that $\mathrm{ON}$ and OFF M LGN cells from one eye converge before ocular inputs are combined in more superficial cortical layers. Yet, the same may not be the case for the P LGN cells since many of their target cells in IV have been reported to have receptive fields that are identical to $\mathrm{P}$ cells in the $\mathrm{LGN}^{14}$ (see, however, Leventhal et al. ${ }^{21}$ ). Anatomically, layer IV sends projections to cells within layer III which are known to mix ON and OFF and ocular inputs. Thus, it is unclear in this primate species whether ON/OFF convergence and binocular convergence occur as a single event or serially. With respect to the latter it is noteworthy that recent psychophysical studies of humans indicate that, for some tasks requiring depth judgements, increments and decrements of brightness, presumably carried by the $\mathrm{ON}$ and OFF channels to cortex, are treated independently by each eye within the early stages (e.g. V1) of processing. ${ }^{22}$ This finding would indicate that at least some aspects of stereopsis involve cells that combine ocular pathways before ON or OFF pathways. It would be interesting to determine whether such cells can be found in the macaque monkey V1 and if so where they are located anatomically.

In tree shrews, close relatives of primates, anatomical and physiological studies ${ }^{9,11}$ have provided clear support for serial convergence of inputs such that ipsi- and contralateral ocular inputs are combined before the ON/OFF centre pathways. However, it is not clear whether tree shrews have stereopsis. Moreover, other primates in which there is evidence of stereopsis, such as bush babies ${ }^{23}$ and squirrel monkeys ${ }^{24}$ have cells within input layer IV that are frequently ON/OFF and monocular (bush babies) or ON/OFF and binocular (squirrel monkeys). Moreover in cats, which have also been shown to exhibit stereopsis, direct physiological exmination reveals that $\mathrm{ON}$ and OFF and left and right eye pathways can all converge at the first synapse in cortex $^{25}$ (see Fig. 2). Taken together, these findings suggest that different species may have different solutions to the problem of combining binocular inputs, although direct evidence is lacking.

Concerning parallel channels, a related issue is whether all channels participate equally in binocular single vision, particularly stereopsis. Livingstone and Hube $^{26}$ have suggested that stereopsis is handled primarily by the $\mathrm{M}$ retinal channel. Evidence to support this comes from data which show that cells in IIIC, which receive heavy input from the $M$ pathway via IV $\alpha$ in $V 1$, have a large number of binocular cells 
that are selective for disparity. These cells project to bands of cells in V2 and to area MT that also contain a high proportion of disparity-selective cells. ${ }^{26,27}$ However, lesions of M LGN layers and area MT do not affect stereo vision in macaque monkeys. ${ }^{28,29}$ While the $M$ pathway is thus not necessary for stereopsis, it probably does contribute to it, given the presence of good stereopsis under scotopic conditions $^{30}$ and the fact that $\mathrm{M}$, but not $\mathrm{P}$, retinal ganglion cells near the fovea receive input from rods. ${ }^{31}$ Psychophysical studies show that stereopsis is maintained at isoluminance, ${ }^{32}$ suggesting the involvement of the colour-opponent $\mathrm{P}$ pathway in stereopsis. Lesions of the LGN P layers do disrupt stereopsis but only when the image is made up of high spatial frequencies to which $M$ cells respond poorly. ${ }^{28}$ It seems likely that both $M$ or $P$ channels can contribute to stereopsis depending on the contrast and spatial frequency of the stimulus. This is not surprising, given anatomical evidence that the $\mathrm{P}$ and $\mathrm{M}$ channels (and possibly also the $\mathrm{K}$ channel) are combined early in $\mathrm{V} 1 .^{33}$

\section{BINOCULARITY AND THE LGN}

The spatial maps of each of the LGN layers are in precise register such that a single point in visual space (e.g. $X$ in Fig. 1) is represented as a line (the line of projection ${ }^{34}$ ) running roughly perpendicular to the long axis of the layers. Given the segregation of ocular inputs in the LGN, the tight retinotopic register of each layer with its neighbours suggests the presence of binocular interactions in the LGN. In fact, the alignment of common points (e.g. $\mathrm{X}$ in Fig. 1) from layer to layer is so precise that cellular gaps appear at the laminar representation of the visually blind optic disc (OD in Fig. 1) in all contralaterally innervated LGN layers. This allows contralateral layers to remain exactly aligned with their ipsilaterally innervated LGN counterparts, such that projections across laminar borders would remain in the same location in the visual field. Dendrites of LGN cells have been shown to cross laminar borders in just such a fashion, ${ }^{35,36}$ as have the axons of the feedback pathway from layer VI of visual cortex. ${ }^{37-39}$ These pathways probably mediate the inhibition that is generated in many LGN neurons by stimulation of the non-dominant eye. ${ }^{40-44}$ Both short-latency inhibition that is not selective for orientation, and longer-latency, orientation-selective inhibition (but see Sengpiel et $a l^{44 a}$ ) is seen; the former probably represents interactions at the LGN while the latter is probably the result of the corticogeniculate pathway.

Although the function of binocular interactions in the LGN is unclear, several investigators have suggested that they aid in the process of binocular fusion for stereopsis. ${ }^{41,43,45}$ McIlwain $^{45}$ nicely summarises these views in a recent theoretical paper.

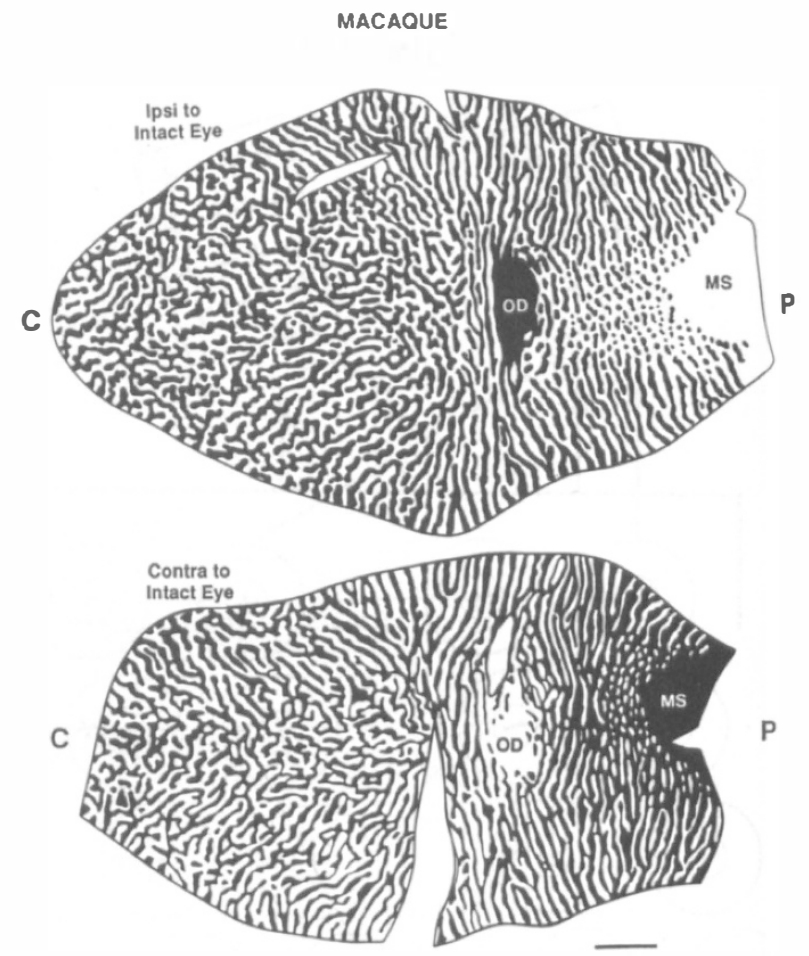

Fig. 3. Distributions of ocular dominance columns in a macaque monkey reconstructed from a montage of sections cut through layer IV of area VI after flattening the cortical tissue. The columns are demonstrated in a cytochrome oxidase stain following blockade of activity from one eye. The dark bands present the intact eye. The patterns ipsilateral (above) and contralateral (below) to the intact eye are similar but not identical. The entire visual field is represented from central $(C)$ to peripheral $(P)$. The representation of the optic disc $(O D)$ of the nasal retina is centred 17 degrees from the fovea. The unbanded segments to the right correspond to the monocular segment (MS) of the visual field. Scale bar represents $5 \mathrm{~mm}$. From Florence and Kaas ${ }^{48}$ with permission of the publishers.

Basically, the visual system is faced with a geometric problem. The problem is that two retinal loci that are optically in register at one visual fixation distance are not in register at other fixation distances. It has been proposed that visual cortical neurons that code disparity are important for stereopsis. Since these cells are known to respond to a very narrow range of disparities, either the visual cortex needs a lot of these cells tuned to each disparity at each locus or the disparity tuning of individual cells is dynamically adjusted. Originally Schmielau and Singer ${ }^{41}$ suggested that dynamic disparity tuning could be accomplished within the LGN via binocular feedback from V1 corticogeniculate axons.

Verela and Singer, ${ }^{43}$ using dichoptic stimulation in which a horizontal square-wave drifting grating was used to activate cat LGN cells through the dominant eye and intermittent stimulation using another grating was used to stimulate the non-dominant eye, showed that suppression caused by stimulation of the non-dominant eye was strongest when the two 


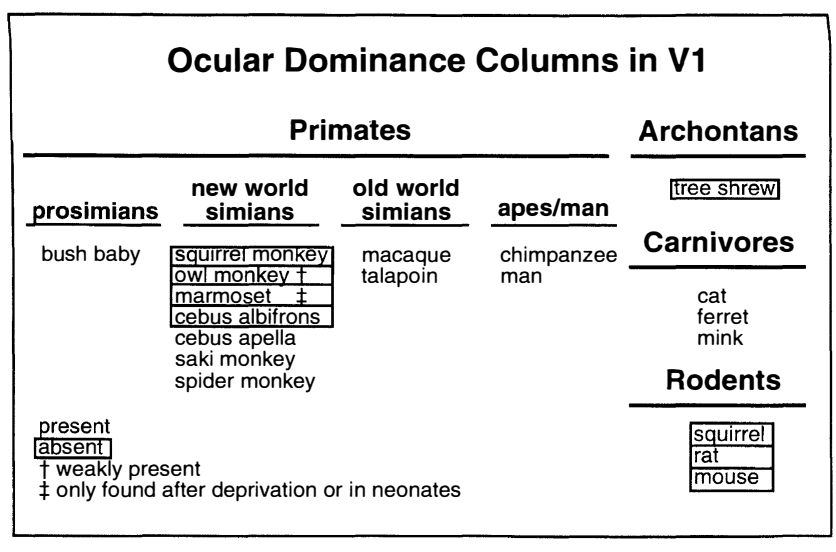

Fig. 4. Presence or absence of ocular dominance columns for a selection of primate and non-primate species. Names of species without ocular dominance columins are in grey rectangles. Ocular dominance columns have been found in all Old World monkeys and apes examined, but are found in only some New World monkeys. In some of these species (marked with a dagger or asterisk, respectively) columns are only weakly present, or their formation can be induced (or stabilised) with early deprivation. Note that ocular dominance columns are also present in certain non-primates such as carnivores.

gratings differed most in orientation. Such pairs of grating stimuli are known to cause binocular rivalry. On the basis of these experiments Verela and Singer ${ }^{43}$ hypothesised that the afferents from the visual cortex play an important role in modifying the signal-to-noise ratio based on congruency between ongoing cortical activation and retinal activation. In the light of this hypothesis it is interesting that local iontophoresis of glutamate within layer VI of striate cortex has been shown to produce facilitation of LGN cell responses if the receptive field of the LGN cell is aligned within 1-3 degrees of the retinotopic location of the cortical stimulation. If the field is misaligned with the cortical stimulation site, inhibitory effects occur. ${ }^{46}$ If the corticogeniculate pathway is involved in dynamic disparity tuning of cortical cells, then one would predict that the receptive fields of LGN and binocular cortical neurons would not be fixed on the retina during active viewing conditions with varying fixation requìrements. Although some evidence of such dynamic changes in the receptive field properties of cortical neurons exists, there are no data showing such changes in LGN receptive fields. Specifically, one would predict that changes in vergence should produce small displacements in the LGN receptive fields relative to the retinal receptive field. ${ }^{43}$ No one has yet looked for such changes.

One anatomical prediction of such a hypothesis is that corticogeniculate axons be restricted to, or be more heavily represented within, the binocular segment of the nucleus. This does not appear to be the case, although systematic examination of corticogeniculate innervation of the two segments of the
LGN has not been done. Moreover, it seems likely that this feedback pathway plays several roles. In the light of our earlier discussions of the relative roles of different functional channels (e.g. ON, OFF or M, P and $\mathrm{K}$ ) it is noteworthy that corticogeniculate axons have been found within all LGN layers as well as the interlaminar zones.

\section{BINOCULARITY IN CORTEX: WHY DO WE HAVE OCULAR DOMINANCE COLUMNS?}

The presence of ocular dominance bands or columns in the visual cortex of some primates (see Fig. 3) has been assumed, logically, to play some important role in binocular interactions, perhaps stereopsis. These columns have been featured as a centrepiece of functional organisation of V1 in most neurobiology textbooks. Yet their functional role has never been established. As shown in Fig. 4, ocular dominance columns occur in all Old World prosimians and simians that have been examined, as well as in chimpanzees and man; other apes have not been examined. ${ }^{47,48}$ They appear in some but not all New World primates. And in some cases, such as in marmosets, ocular dominance columns are only evident either in early development ${ }^{49}$ or if vision in one eye has been compromised early in development. ${ }^{50}$

Ocular dominance columns have also been identified in non-primates including several carnivores (e.g. cat, mink, ferret) and perhaps also in sheep, ${ }^{51}$ but are not present in other species with good vision such as squirrels ${ }^{52}$ and tree shrews. ${ }^{53}$ Attempts to correlate the presence or absence of ocular dominance columns with other features of an animal's visual life style have so far failed. ${ }^{47.48}$ The presence of ocular dominance columns does not appear to be correlated with diurnal or nocturnal vision, presence of trichromatic colour vision, or body size. However, New World primates that have ocular dominance columns do tend to be larger with more widely separated eyes, suggesting a link with stereopsis. A direct test of the hypothesis that ocular dominance columns are important for stereoscopic vision yielded negative results. Squirrel monkeys lack anatomically defined ocular dominance columns ${ }^{54}$ and have few monocularly driven cells in $\mathrm{V} 1{ }^{26}$ Yet, a recent study using evoked potentials to measure the responses of awake squirrel monkeys to the presence of randomdot stereograms suggests that these primates do have stereoscopic vision. ${ }^{24}$ This casts doubt on the assumption that ocular dominance columns play an essential role in stereopsis.

It has been suggested that ocular dominance columns are the developmental outcome of competitive interactions between cells with different firing patterns, and a tendency for cells with common firing patterns to connect with one another. ${ }^{55}$ The 
production of ocular dominance stripes from two eyes forced to share space in the optic tectum of three-eyed frogs ${ }^{56}$ certainly supports such a possibility. In species with ocular dominance columns, activity-dependent competitive interactions in the cortex between terminals driven by the two eyes have been well studied. ${ }^{57}$ After early monocular lidsuture, ocular dominance columns of the deprived eye become smaller, and the loss of terminal space in cortex is reflected by the shrinkage of deprived eyedriven LGN neurons. ${ }^{58,59}$ In monocularly deprived squirrel monkeys, a similar shrinkage of LGN neurons occurs ${ }^{60}$ suggesting that competition within cortex of geniculate fibres representing the two eyes does occur in species that do not have ocular dominance columns. Apparently, competition between two sets of innervating axons is not, in itself, a sufficient condition for the development of columns.

Moreover, if ocular dominance columns are only an epiphenomenon of early competitive interactions between monocular LGN axons in layer IV of V1, then it is curious that the ocular bias in organisation is replayed within V1 cells above and below this layer. This can easily be appreciated from single unit recording or functional maps of the uptake of 2deoxyglucose (2DG) following monocular stimulation or from the rapid downregulation of immediate early gene expression following monocular compromise of vision. ${ }^{61,62}$ Evidence suggests that ocular dominance columns in macaque layer III are, in part, sharpened by inhibitory intracortical connections. ${ }^{63}$ In addition, other functionally defined compartments of V1 such as CO blobs appear aligned with ocular dominance columns, ${ }^{64}$ suggesting that these columns have functional significance. Taken together, these findings suggest that there may be different evolutionary solutions to the binocular fusion problem, although essential details on the binocular visual abilities of different species are still lacking.

\section{CONCLUSIONS}

At the beginning of this article we posed three questions related to the anatomy of binocular vision. First, we asked whether all classes of retinal ganglion cells contribute signals that are important to stereoscopic depth perception or only one class. Data support the conclusion that at least the $\mathrm{P}, \mathrm{M}, \mathrm{ON}$ and OFF channels set up at the retina contribute to the perception of depth. However, it is presently unclear how the cortex combines the monocular signals from each of these channels. It would be particularly interesting to know how deletion of individual channels at the retina or LGN would affect binocular receptive fields within $\mathrm{V} 1$. Second, we asked whether the dorsal lateral geniculate nucleus (LGN) plays any special role in binocular vision. Although some findings and theories support such a view, the data are not sufficient at present to be certain whether this is the case. Selective deletions of the corticogeniculate pathway have not been tried although such an experiment might be possible in cats where it has been shown that axons from V1 to the LGN travel in a discrete bundle in the white matter. Also, careful analysis of the interactions between individual corticogeniculate axons with LGN layers, and LGN interneurons and relay cells in primates might prove useful in this regard. Finally, we questioned whether ocular dominance columns of primary visual cortex are important to binocularity and stereopsis. Evidence suggests that such segregation of ocular inputs in V1 is not essential to stereopsis. However, the behavioural data are limited. The idea that ocular segregation is an epiphenomenon of developmental Hebbian synaptic rules is not satisfying since it fails to explain why ocular segregation does not always occur; nor does it explain what allows binocular cells to develop. Studies examining the binocular visual abilities of different primates with and without ocular dominance columns could help to resolve this issue since it still may be the case that the presence and absence of ocular dominance columns are associated with specific aspects of stereopsis.

We thank A. Wiencken for comments on the manuscript and B. Martin and J. Mavity-Hudson for help with the illustrations. This work was supported by EY01778 and core grants EY08126 and HD15052.

Key words: Lateral geniculate nucleus, Ocular dominance columns, Parallel pathways, Retina, Visual cortex.

\section{REFERENCES}

1. Casagrande VA, Kaas JH. The afferent, intrinsic, and efferent connections of primary visual cortex in primates. In: Peters A, Rockland KS, editors. Cerebral cortex. New York: Plenum Press, 1994:201-59.

2. Casagrande VA, Norton TT. Lateral geniculate nucleus: a review of its physiology and function. In: Leventhal AG, editor. The neural basis of visual function. Houndmills, Basingstoke: Macmillan Press, 1991:41-84.

3. Weber AJ, Kalil RE, Behan M. Synaptic connections between corticogeniculate axons and interneurons in the dorsal lateral geniculate nucleus of the cat. J Comp Neurol 1989;289:156-64.

4. Sherman SM, Koch C. The control of retinogeniculate transmission in the mammalian lateral geniculate nucleus. Exp Brain Res 1986;63:1-20.

5. Harting JK, Van Lieshout DP, Hahikawa T, Weber JT. The parabigeminogeniculate projection: connectional studies in eight mammals. J Comp Neurol 1991; 305:559-81.

6. Feig S, Harting JK. Ultrastructural studies of the primate lateral geniculate nucleus: morphology and spatial relationships of axon terminals arising from the retina, visual cortex (area 17), superior colliculus, parabigeminal nucleus, and pretectum of Galago crassicaudatus. J Comp Neurol 1994;343:17-34.

7. Harting JK, Hashikawa T, Van Lieshout D. Laminar distribution of tectal, parabigeminal and pretectal 
inputs to the primate dorsal lateral geniculate nucleus: connectional studies in Galago crassicaudatus. Brain Res 1986;366:358-63.

8. Conley M, Fitzpatrick D, Diamond IT. The laminar organisation of the lateral geniculate body and the striate cortex in the tree shrew (Tupaia glis). J Neurosci 1984;4:171-97.

9. Kretz R, Rager G, Norton TT. Laminar organisation of $\mathrm{ON}$ and OFF regions and ocular dominance in the tree shrew (Tupaia belengeri). J Comp Neurol 1986;251: 135-45.

10. Fitzpatrick D, Raczkowski D. Innervation patterns of single physiologically identified geniculocortical axons in the striate cortex of the tree shrew. Proc Natl Acad Sci USA 1990;87:449-53.

11. Muly EC, Fitzpatrick D. The morphological basis for binocular and ON/OFF convergence in tree shrew striate cortex. J Neurosci 1992;12:1319-34.

12. Lachica EA, Casagrande VA. Direct W-like geniculate projections to the cytochrome oxidase $(\mathrm{CO})$ blobs in primate visual cortex: axon morphology. J Comp Neurol 1992;319:141-58.

13. Ding Y, Casagrande VA. The morphology of LGN axons that terminate in the CO blobs of primate V1. Soc Neurosci Abstr 1995;21:394.

14. Livingstone MS, Hubel DH. Anatomy and physiology of a colour system in the primate visual cortex. J Neurosci 1984;4:309-56.

15. DeBruyn EJ, Casagrande VA, Beck PD, Bonds AB. Visual resolution and sensitivity of single cells in the primary visual cortex (V1) of a nocturnal primate (bush baby): correlation with cortical layers and cytochrome oxidase patterns. J Neurophysiol 1993; 69:3-18.

16. Blasdel GG, Fitzpatrick D. Physiological organisation of layer 4 in macaque striate cortex. J Neurosci 1984;4:880-95.

17. Barlow HB, Blakemore C, Pettigrew JD. The neural mechanism of binocular depth discrimination. J Physiol (Lond) 1967;193:327-42.

18. Wässle $\mathrm{H}$, Boycott $\mathrm{BB}$, Illing RB. Morphology and mosaic of on- and off-beta cells in the cat retina and some functional considerations. Proc R Soc Lond B 1981;212:177-95.

19. Hubel DH, Wiesel TN. Receptive fields and functional architecture of monkey striate cortex. J Physiol (Lond) 1968;195:215-43.

20. Bullier J, Henry GH. Ordinal position and afferent input of neurons in monkey striate cortex. J Comp Neurol 1980;193:913-35.

21. Leventhal AG, Thompson KG, Liu D, Zhou Y, Ault SJ. Concomitant sensitivity to orientation, direction and colour of cells in layers 2, 3 and 4 of monkey striate cortex. J Neurosci 1995; 15:1808-18.

22. Bullock TH. How are more complex brains different? Brain Behav Evol 1995;41:88-96.

23. Treff H-A. Tiefensehschärfe und Sehschärfe beim Galago (Galago senegalensis). Z Vergleichende Physiol 1967;54:26-57.

24. Livingstone MS, Nori S, Freeman DC, Hubel DH. Stereopsis and binocularity in the squirrel monkey. Vision Res 1995;35:345-54.

25. Tanaka K. Organisation of geniculate inputs to visual cortical cells in the cat. Vision Res 1985;25:357-64.

26. Hubel DH, Livingstone MS. Segregation of form, colour and stereopsis in primate area 18 . J Neurosci 1987;7:3378-415.

27. Maunsell JHR, van Essen DC. Functional properties of neurons in middle temporal visual area of the macaque monkey. II. Binocular interactions and sensitivity to binocular disparity. J Neurophysiol 1983;49:1148-67.

28. Schiller PH, Logothetis NK, Charles ER. Role of the colour-opponent and broad-band channels in vision. Vis Neurosci 1990;5:321-46.

29. Schiller PH. The effects of V4 and middle temporal (MT) area lesions on visual performance in the rhesus monkey. Vis Neurosci 1993;10:717-46.

30. Livingstone MS, Hubel DH. Stereopsis and positional acuity under dark adaptation. Vision Res 1994; 34:799-802.

31. Purpura K, Kaplan E, Shapley RM. Background light and the contrast gain of primate $\mathrm{P}$ and $\mathrm{M}$ retinal ganglion cells. Proc Natl Acad Sci USA 1988; 85:4534-7.

32. Schiller PH, Logothetis NK, Charles ER. Parallel pathways in the visual system: their role in perception at isoluminance. Neuropsychologia 1991;29:433-41.

33. Lachica EA, Beck PD, Casagrande VA. Parallel pathways in macaque monkey striate cortex: anatomically defined columns in layer III. Proc Natl Acad Sci USA 1992;89:3566-70.

34. Bishop PO, Burke W, Davis R. The interpretation of the extracellular response of single lateral geniculate cells. J Physiol (Lond) 1962;162:451-72.

35. Guillery RW. A study of Golgi preparations from the dorsal lateral geniculate nucleus of the adult cat. J Comp Neurol 1966;128:21-50.

36. Saini KD, Garey LJ. Morphology of neurons in the lateral geniculate nucleus of the monkey: a Golgi study. Exp Brain Res 1981;42:235-48.

37. Robson JA. The morphology of corticofugal axons to the dorsal lateral geniculate nucleus in the cat. J Comp Neurol 1983;216:89-103.

38. Robson JA. Reconstruction of corticogeniculate axons in the cat. J Comp Neurol 1984;225:193-200.

39. Claps A, Casagrande VA. The distribution and morphology of corticogeniculate axons in ferrets. Brain Res 1990;530:126-9.

40. Sanderson KJ, Bishop PO, Darian-Smith I. The properties of the binocular receptive fields of lateral geniculate neurons. Exp Brain Res 1971;13:178-207.

41. Schmielau F, Singer W. The role of visual cortex in binocular interactions in the cat lateral geniculate nucleus. Brain Res 1977;120:354-61.

42. Rodieck RW, Dreher B. Visual suppression from nondominant eye in the lateral geniculate nucleus: a comparison of cat and monkey. Exp Rain Res 1979;35:465-77.

43. Verela FJ, Singer W. Neuronal dynamics in the visual corticogeniculate pathway revealed through binocular rivalry. Exp Brain Res 1987;66:10-20.

44. Schroeder CE, Tenke CE, Arezzo JC, Vaughan HG. Binocularity in the lateral geniculate nucleus of the alert macaque. Brain Res 1990;521:303-10.

44a. Sengpiel F, Blakemore C, Harrad H. Interocular suppression in the primary visual cortex: a possible basis of binocular rivalry. Vision Res 1995;35:179-95.

45. Mcllwain JT. Lateral geniculate lamination and the corticogeniculate projection: a potential role in binocular vision in the quadrants. $J$ Theor Biol 1995;172:329-33.

46. Tsumoto T, Creutzfeldt OD, Legény CR. Functional organisation of the corticofugal system from visual cortex to lateral geniculate nucleus in the cat (with an appendix on geniculo-cortical mono-synaptic connections). Exp Brain Res 1978;32:345-64.

47. Florence SI, Comley M, Casagrande VA. Ocular dominance projections and retinal projections in new 
world spider monkeys (Ateles ater). J Comp Neurol 1986;243:234-48.

48. Florence SL, Kaas JH. Ocular dominance columns in area 17 of Old World macaque and talapoin monkeys: complete reconstructions and quantitative analyses. Vis Neurosci 1992;8:449-62.

49. Spatz WB. Loss of ocular dominance columns with maturity in the monkey, Callithrix jacchus. Brain Res 1989;488:376-80.

50. DeBruyn EJ, Casagrande VA. Demonstration of ocular dominance columns in a New World primate by means of monocular deprivation. Brain Res 1981;207:453-8.

51. Pettigrew JD, Ramachandran VS, Bravo H. Some neural connections subserving binocular vision in ungulates. Brain Behav Evol 1984;24:65-93.

52. Weber JT, Casagrande VA, Harting JK. Transneuronal transport of $\left[{ }^{3} \mathrm{H}\right]$ proline within the visual system of the grey squirrel. Brain Res 1977;129:346-52.

53. Casagrande VA, Harting JK. Transneuronal transport of tritiated fucose and proline in the visual pathways of tree shrew Tupaia glis. Brain Res 1975;96:367-72.

54. Hendrickson AE, Wilson JR, Ogren MP. Neuroanatomical organisation of pathways between the dorsal lateral geniculate nucleus and visual cortex in Old World and New World primates. J Comp Neurol 1978;182:123-36.

55. Purves D, Riddle DR, LaMantia A-S. Iterated patterns of brain circuitry (or how the cortex gets its spots). Trends Neurosci 1992;15:362-8.

56. Law MI, Constantine-Paton M. Anatomy and physiol- ogy of experimentally produced striped tecta. J Neurosci 1981;1:741-59.

57. Mitchell DE, Timney B. Postnatal development of function in the mammalian visual system. In: Brookhart JM, Mountcastle VB, editors. Handbook of physiology. American Physiological Society, 1984.

58. Wiesel TN, Hubel DH. Effects of visual deprivation on morphology and physiology of cells in the cat's lateral geniculate body. J Neurophysiol 1963;26:978-93.

59. Hubel DH, Wiesel TN, LeVay S. Plasticity of ocular dominance columns in monkey striate cortex. Phil Trans R Soc Lond B 1977;278:377-409.

60. Tigges $\mathrm{M}$, Hendrickson AE, Tigges J. Anatomical consequences of long-term monocular closure on lateral geniculate nucleus and striate cortex in squirrel monkey. J Comp Neurol 1984;227:1-13.

61. Tootell RBH, Hamilton SL, Silverman MS, Switkes E. Functional anatomy of macaque striate cortex. I. Ocular dominance, binocular interactions and baseline conditions. J Neurosci 1988;8:1500-30.

62. Chaudhuri A, Matsubara JA, Cynader MS. Neuronal activity in primate visual cortex assessed by immunostaining for the transcription factor Zif268. Vis Neurosci 1995;12:35-50.

63. Blasdel GG, Haglund MM. Bicuculline induced disruption of optically determined ocular dominance bands in macaque striate cortex. Soc Neurosci Abstr 1989;15:799.

64. Horton JC. Cytochrome oxidase patches: a new cytoarchitectonic feature of monkey visual cortex. Phil Trans R Soc Lond B 1984;304:199-253. 